\title{
Psicologia e Políticas de Saúde da População Trans: Encruzilhadas, Disputas e Porosidades
}

\author{
Erick da Silva Vieira ${ }^{1}$ \\ ${ }^{1}$ Universidade Federal do Rio de Janeiro, \\ Rio de Janeiro, Brasil. \\ Carlos Allencar Servulo Rezende Pereira ${ }^{1}$ \\ ${ }^{1}$ Universidade Federal do Rio de Janeiro, \\ Rio de Janeiro, Brasil.
}

\author{
Clarissa Viola Dutra ${ }^{1}$ \\ ${ }^{1}$ Universidade Federal do Rio de Janeiro, \\ Rio de Janeiro, Brasil. \\ Céu Silva Cavalcanti ${ }^{1}$ \\ ${ }^{1}$ Universidade Federal do Rio de Janeiro, \\ Rio de Janeiro, Brasil.
}

Resumo: Este texto se propõe a compor uma reflexão sobre algumas fronteiras que atravessam a Psicologia quando posta em contato com as demandas dos segmentos trans e com a operacionalização de políticas de saúde para este segmento. Um rápido levantamento das políticas de saúde nos possibilita entender como suas construções apontam diferentes entendimentos tanto sobre a própria experiência trans quanto sobre as dinâmicas de poder que instituem a norma cisgênera como centralidade e régua a partir da qual são medidas as experiências. A ambiguidade posta é atentar que na medida em que garantir o acesso universalizado aos serviços, bem como amplificar sua oferta, é necessidade a ser pautada com urgências, as práticas cotidianas dos profissionais destes espaços vai produzir o tom de toda a política, marcando esta como emancipatória e acolhedora ou como apenas mais um reforço das normas da cisgeneridade naturalizada e compulsória. A Psicologia, aqui cremos, ocupa um lugar estratégico dada a sua produção enquanto campo que afirma as autodeterminações de gênero e se capilariza nos mais diversos nichos do sistema de saúde, inclusive na atenção básica. Por fim, atentar para as normas que atravessam a proposição e efetivação das políticas de saúde para a população trans é exercício fundamental para que possamos estabelecer práticas despatologizantes e finalmente abdicar da produção constante de "especialistas" imbuídos por um conjunto de relações de poder, de dizer sobre o outro suas supostas verdades, produzindo exclusões das vivências que não caibam nos restritos manuais biomédicos.

Palavras-chave: Políticas de Saúde, Psicologia, Cisgeneridade, Pessoas Trans. 


\title{
Psychology and Trans Population's Health Policies: Crossroads, Disputes and Porosities
}

\begin{abstract}
This text proposes to compose a reflection about some frontiers that cross the psychology when put in contact with the demands of the trans segments and with the operationalization of health policies for this segment. A rapid survey of health policies enables us to understand how their constructions point to different understandings both of the trans experience itself and of the power dynamics that establish the cisgender norm as the centrality and rule from which the experiences are measured. The ambiguity posed is that to the extent that guaranteeing universalized access to services, as well as amplifying their offer is a necessity to be ruled with urgencies, the daily practices of professionals of these spaces will produce the tone of the whole policy, marking this as emancipatory and welcoming or just another reinforcement of the norms of naturalized and compulsory cisgenerity. Psychology, here we believe, occupies a strategic place given its production as a field that affirms the self-determination of gender and capillarizes itself in the most diverse niches of the health system, including basic attention. Finally, attention to the norms that cross the proposition and effectiveness of health policies for the trans people is a fundamental exercise so that we can establish depathologizing practices and finally abdicate the constant production of "specialists" imbued by a set of relations of power, of telling others about their supposed truths, producing exclusions from experiences that do not fit in the restricted biomedical manuals.
\end{abstract}

Keywords: Health Policies, Psychology, Cisgenerity, Trans People.

\section{Psicología y Políticas de Salud da Población Trans: Encrucijadas, Disputas y Porosidades}

Resumen: Este texto intenta componer una reflexión sobre algunos límites que cruzan la psicología cuando está en contacto con las demandas de los segmentos trans y la operacionalización de las políticas de salud para este segmento. Una encuesta rápida de las políticas de salud nos permite comprender cómo sus construcciones apuntan a diferentes interpretaciones tanto de la experiencia trans en sí como de la dinámica de poder que instituye la norma cisgénero como la centralidad y la regla a partir de la cual se miden las experiencias. La ambigüedad planteada es tener en cuenta que, en la medida en que se garantiza el acceso universalizado a los servicios, así como ampliar su oferta, es una necesidad que debe regirse con urgencia, las prácticas diarias de los profesionales de estos espacios marcarán el tono de toda la política, marcando esto como emancipatorio y acogedor o simplemente como un refuerzo de las normas de cisgeneridad naturalizada y obligatoria. La Psicología, aquí creemos, ocupa un lugar estratégico dada su producción como un campo que afirma las autodeterminaciones de género y se capilariza en los nichos más diversos del sistema de salud, incluida la atención primaria. Finalmente, prestar atención a las reglas que cruzan la propuesta y la implementación de políticas de salud para la población trans es un ejercicio fundamental para nosotros para establecer prácticas de despatologización y finalmente abdicar de la producción constante de "especialistas" imbuidos por un conjunto de relaciones de poder, contar sobre el otro sus supuestas verdades, produciendo exclusiones de experiencias que no se ajustan a los manuales biomédicos restringidos.

Palabras clave: Políticas de Salud, Psicología, Cisgeneridad, Personas Trans. 


\section{Introdução}

Entender as relações densas que atravessam as dinâmicas institucionais e as políticas públicas quando em relação com as pessoas trans nos convida a perceber atravessamentos complexos que organizam constantemente diferentes campos que aqui tem ponto de encontro. Propomos, com as reflexões que aqui apresentamos, pensar como a Psicologia enquanto campo de saber-poder habita uma zona de fronteira no campo das políticas de saúde direcionadas às populações trans. Uma bifurcação aqui é acionada: por uma via, um conjunto de produções desde a Psicologia a alocam em posição de vanguarda ao ser espaço teórico, prático e político da defesa do conceito de autodeterminação de gênero e mesmo no uso da cisgeneridade como conceito analítico (Cavalcanti, Carvalho \& Bicalho, 2018). Em outra direção, parte também do campo da Psicologia uma série de enunciados que busca reiterar constantemente a norma cisgênera por via de perspectivas patologizantes, tecendo toda uma rede discursiva que captura as vidas trans - nas perspectivas por vezes estreitas - dos profissionais que se entendem como "especialistas".

A problemática aqui proposta é como entender as políticas de saúde oferecidas para a população trans atentando para as porosidades e brechas que permitam apontar reordenamentos de racionalidades supostamente estáticas. Como chave analítica, cremos que operar entendendo como a experiência da cisgeneridade se institui como centralidade nas possibilidades de experienciar o gênero e o corpo. Para tanto, cabe apontar que pensamos cisgeneridade em concordância com o proposto por Viviane Vergueiro (2016) que entende que a cisgeneridade se institui como norma e como regime a partir de três instâncias: a pré-discursividade, a binaridade e a permanência. Para a autora, as três seriam interligadas e falariam de organizações de poder que como efeito produzem um suposto caráter de natureza e destino às vidas cisgêneras ao mesmo tempo em que produz percepções de que vivências que se afastem dessa linha sejam entendidas como erros e patologias a serem corrigidas.

Vivemos um momento histórico e político ímpar para as populações trans, posto que as reivindicações dos diferentes movimentos sociais começam a produzir, nesta geração, capilarizações em diferentes instituições e políticas. Não raro, pessoas trans (ainda que poucas) começam a ocupar espaços na academia, nas casas legislativas e nos campos de deliberação, fato que, como eco, redimensiona antigos debates sempre feitos sobre pessoas trans e que agora passam a ser feitos com e para pessoas trans. Cabe destacar as grandes reverberações possibilitadas a partir da campanha nomeada como Stop Trans Pathologization (STP 2012) que, visando a modificação periódica dos grandes manuais da taxonomia médica, mobiliza ativistas e pessoas acadêmicas de diversos países na tentativa de estabelecer um diálogo direto com as grandes organizações de saúde responsáveis por categorizar as doenças. Após um conjunto de atravessamentos, a Organização Mundial de Saúde (OMS) anuncia em 2018 que em seu próximo manual (CID 11) as experiências trans não mais constarão no capítulo dos transtornos mentais.

As lutas políticas de diferentes movimentos trans, associadas a toda uma produção teórica recente que passa a questionar a patologização e objetificação de pessoas não cis convida os campos das políticas de saúde a constantemente se repensarem. Tais movimentações, que hora são acolhidas, hora encontram resistências e reorganizações discursivas tecem cartografias importantes para perceber deslocamentos de poder e composições heterogêneas de dispositivos atravessados por disputas históricas.

Podemos refletir sobre como algumas interpelações fundam nossas subjetividades (e aqui pensamos também as subjetividades trans, mas não só). Paul Preciado (2014) pensa nos processos de interpelação constitutiva como um conjunto de tecnologias médico-discursivas que produzem corpos generificados desde antes destes corpos nascerem. Para ele, é como que uma mesa de operações abstratas na qual todas as pessoas têm a verdade de si e de seu corpo produzidas a partir da interpelação de uma "tecnologia biopolítica custosa” (Preciado, 2014, p. 128). Como efeito dessas operações abstratas, têm-se corpos marcados pelos dispositivos de gênero e estabilizados por um conjunto de tecnologias discursivas, políticas, estéticas. Performatividade aqui também se soma como um conceito que nos ajuda a perceber o caráter arbitrário do gênero que só é supostamente estabilizado a partir de um violento conjunto de normas impostas cotidianamente a todas as pessoas. O efeito de toda essa maquinaria é a produção da cisgeneridade como destino e como régua para pensar normalidades dos corpos (Vergueiro, 2016).

Viviane Vergueiro (2016) pensa a cisgeneridade a partir de três elementos: pré-discursividade, binari- 
dade e permanência. Estes três elementos nos ajudam a entender como uma lógica de autocentramento permeia a percepção de pessoas não trans (cis) sobre experiências trans. A pré-discursividade seria o entendimento coletivamente difundido de que há características "naturais" e traços anteriores às próprias conformações da cultura na definição das identidades de gênero (Vergueiro, 2016). Tal premissa, ainda que duramente questionada pelas teorias da performatividade seguem delineando imaginários hierarquizantes que entendem os corpos cis como "verdadeiros" em detrimento dos corpos trans como "falsos" ou "imitações". Ainda para Viviane (2016), a segunda característica da cisgeneridade é a binaridade. Uma vez que se defende um status de "normalidade" marcado por instâncias anteriores ao discurso, a composição dos corpos cisgêneros necessariamente decorre de uma diferenciação binária entre homens/machos e mulheres/fêmeas. A rigidez da demarcação das fronteiras aqui estabelecidas compõe a própria noção da cisgeneridade como destino, posto que as ditas instâncias seriam pares opostos cujas diferenças são naturalmente firmadas. O terceiro elemento intersecciona-se com os dois já apresentados e opera também de forma a invalidar as verdades dos corpos trans. Viviane demarca como permanência, a instância que pressupõe uma suposta coerência na autodefinição da cisgeneridade. Nessa concepção, qualquer desvio do destino deverá ser considerado patológico, uma afronta à natureza e ao estado intrínseco dos corpos e identidades de gênero. Aqui tem-se um conjunto de expectativas sobre os corpos que operam durante toda a vida sempre partindo de roteiros pré-fixados. Como efeito direto do mito da permanência das identidades de gênero, experiências trans historicamente têm sido capturadas por discursos ortopédicos e racionalidades invasivas, engessantes e patologizantes.

Colocar a cisgeneridade sob análise - e não apenas a heterossexualidade - aqui nos é fundamental, posto que quando observamos as dinâmicas de captura e anulação das narrativas trans, o que está posto é um modelo de cisgeneridade confundido com o próprio ideal regulatório dos modelos desejados de corpo, de discurso e de subjetividade. Nos faz fundamento, portanto, pensar possibilidades de saúde mental de sujeitos não cisgêneros entendendo que há nas entrelinhas uma inevitável relação com a própria cisgeneridade entendida aqui não como substância, mas como um regime de poder.

\section{Dissonâncias entre Saúde Mental e pessoas Trans}

Refletir sobre o dispositivo da saúde mental para pessoas trans é necessariamente pensar os atravessamentos históricos que a psiquiatria construiu no último século. Como efeito direto, chegamos ao fim da primeira década dos anos 2000 finalmente iniciando os debates sobre a possibilidade de pensar vivências trans para além do discurso e dos enunciados psiquiátricos. O anúncio de que em 2012 os manuais psiquiátricos seriam revistos possibilita a organização de ativistas e pesquisadoras(es) trans que, junto com entidades e atores aliados começam a organizar a campanha a Rede Internacional pela Despatologização Trans. Em um trecho de seu manifesto, a campanha traz que:

Por "psiquiatrização" nomeamos a prática de definir e tratar a transexualidade sob o estatuto de transtorno mental. Referimo-nos, também, à confusão de identidades e corpos não normativos (situados fora da ordem cultural dominante) com identidades e corpos patológicos. A psiquiatrização relega às instituições médico-psiquiátricas o controle sobre as identidades de gênero. A prática oficial de tais instituições, motivada por interesses estatais, religiosos, econômicos e políticos, trabalha sobre os corpos das pessoas amparando e reproduzindo o binômio homem e mulher, fazendo com que esta postura excludente passe por uma realidade natural e "verdadeira”. Tal binômio, pressupõe a existência única de dois corpos (homem ou mulher) e associa um comportamento específico a cada um deles (masculino ou feminino) ao par que, tradicionalmente, tem-se considerado a heterossexualidade como a única relação possível entre eles. Hoje, denunciando este paradigma, que tem utilizado o argumento da biologia e da natureza como justificativa da ordem social vigente, evidenciamos seus efeitos sociais para por fim a suas pretensões políticas (Manifesto da Rede Internacional pela Despatologização trans. 2012. Disponível em https://www.stp2012.info/old/pt/manifesto).

Hoje, em inícios de 2019, o DSM-V suprime o termo transtorno de identidade de gênero contudo inclui o termo disforia de gênero. Ao passo em que o CID 11, da OMS, ainda não publicado, anuncia que a 
experiência trans não mais constará no capítulo de transtornos mentais, mas será incluída no capítulo de condições relativas à saúde sexual. No cerne de todo o jogo, como apontado pelo manifesto da rede pela despatologização, se encontra um constante autocentramento da perspectiva cisgênera como conceito equivalente às normalidades físicas e mentais $\mathrm{e}$ a decorrente impossibilidade de legitimação de toda experiência que se afaste da cisgeneridade enquanto destino. No cerne do debate entre psiquiatria e possibilidades de autonomia das pessoas trans frente seus corpos e desejos, há de se considerar como as redes de saber-poder se produzem violentamente na legitimação de quais corpos, ainda que trans, são mais legítimos que outros. Cria-se pela psiquiatria e seus manuais um conjunto de discursos de verdade que separam as experiências trans em "verdadeiras" ou "falsas". Como efeito perverso, apenas as consideradas "verdadeiras" são possibilitadas ao acesso a tecnologias de saúde inclusive oferecidas pelo sistema universal e gratuito (Souza \& Cavalcanti, 2016).

Cuidado em saúde, para pessoas trans, é muitas vezes confundido com tutela e sob discursos de acolhimento e proteção, profissionais de saúde imprimem sobre os corpos trans, suas próprias perspectivas de destinos cisgêneros (Souza \& Cavalcanti, 2016). No exercício de destrinchar essa malha, observar algumas linhas de poder nos é fundamental e a primeira delas é refletir sobre como os discursos de normalidade que a psiquiatria enquanto campo de saber insere nas vivências trans, produz um suposto binômio disjuntivo entre corpo-mente. A partir dessa falsa dicotomia, baseiam-se uma série de procedimentos e expectativas. Michel Missé (2010), homem trans e um dos idealizadores da campanha STP2012, aponta que um dos efeitos mais perversos da patologização foi o de produzir e legitimar um paradigma único a partir do qual se pensa transições de gênero na nossa cultura. Tal paradigma, pauta-se num conjunto de elementos presentes faz décadas nos manuais de psiquiatria e, ao entender a vivência trans sob a ótica da doença mental (estranha psicose que nega a realidade natural do corpo), insere o sofrimento compulsório como elemento necessariamente encontrável nas vivências trans "verdadeiras". Cria-se o ideal do "corpo errado", que pauta a dicotomia entre mentes de um gênero e corpos de outro. A negação do próprio corpo é aqui fundamental para os saberes médico-psiquiátricos atestarem incongruências e disforias e a régua que mede nossas subjetividades introduz uma dinâmica de poder onde não cabe a nós falarmos sobre nossas verdades, mas sim a profissionais e seus velhos manuais empoeirados.

Nos campos psi (Psicologia, Psiquiatria e Psicanálise), a despatologização trans é pauta em disputa, que toca numa necessária reorganização ou mesmo deslegitimação de campos que historicamente se vestem da arrogância de produzir sobre nós nossos próprios discursos. Não raro, ainda hoje pesquisadoras(es) cisgêneras(os) partem desde um centramento de sua própria cisgeneridade auto-referenciada como normalidade para escrutinar os supostos motivos de uma "Epidemia Transexual" (Jones, 2019), porém seguem desconsiderando todos os fatores sócio-históricos e os pequenos frutos de mudanças que em nossa geração já podemos minimamente vivenciar, mas que são gerados desde lutas densas de várias gerações trans impossibilitadas de vida plena, reconhecimento e acesso a direitos muito básicos.

Pautar despatologização das identidades trans desarticula não só uma rede de poder e um conjunto de dispositivos de governamentalidade, como também desorganiza lucrativos nichos de mercado. Aqui podemos pensar que alguns elementos produzem relações de tutela e dependências que gera dinâmicas clientelistas entre pessoas trans e determinados "especialistas" psis que se pautam desde seus próprios saberes, como imprescindíveis a qualquer transição de gênero. Saúde mental vendida como mercadoria é elemento que interpela as vivências trans, mas que, em tempos de acirramento de lógicas liberais atravessa toda uma composição das ferramentas psi.

\section{Marcos históricos para garantia do acesso da população trans ao Sistema Único de Saúde}

Em agosto de 2008, por meio da Portaria $n^{\circ} 1.707 / G M / M S$ e da Portaria no 457 /SAS/MS, o processo transsexualizador e os procedimentos a ele associados foram instituídos no Sistema Único de Saúde (SUS), sendo passível de ser realizado em cinco Hospitais Universitários do país, nas cidades de Porto Alegre/RS, Rio de Janeiro/RJ, Goiânia/GO, São Paulo/SP e Recife/PE. Com a publicação desses documentos, materializou-se o esforço, bastante anterior, da população trans em garantir seu acesso ao direito constitucional à saúde, por meio de cuidados que incidam sobre questões de saúde características da 
vivência dessas pessoas. Essa Portaria foi uma baliza na luta por substituir a lógica marginalizante e invisibilizadora que marca a (des)atenção do Estado frente às demandas dessa população. Anterior a isso, havia sido assegurado o uso do nome social nos documentos de identificação dos equipamentos de saúde do SUS em 2006, através da Carta dos Direitos dos Usuários do SUS (Popadiuk, Oliveira, \& Signorelli, 2017).

Mesmo com esses progressos, a resistência de pessoas trans em serem usuários dos serviços de saúde expõe a realidade de discriminação e preconceito vivenciadas na relação com os profissionais que operam esse sistema (Rocon, Rodrigues, Zamboni, \& Pedrini, 2016). Esse conflito aparece desde o primeiro fluxo massivo de pessoas trans em busca de ajuda médica, nos anos 1980, com a epidemia de HIV/AIDS (Brasil, 2005). Identificados como grupo de risco e com alta prevalência da infecção, o desacolhimento experienciado por essas pessoas em espaços de saúde que não estavam preparados para recebê-las foi - e ainda é - uma das razões que cotidianamente as distanciam do SUS (Roconet al., 2016). Não à toa, os avanços em tornar o sistema mais inclusivo, com a inscrição desse grupo nas práticas e políticas de saúde pública, mostram-se como efeito do tensionamento sustentado por movimentos LGBTs frente ao poder público. As conquistas supracitadas foram precedidas pela presença dos movimentos em espaços de debate, tais como nas Conferências de Políticas Públicas para LGBTs e nos Conselhos de Saúde (Popadiuk et al., 2017).

Em 2004, foi institucionalizado o Programa "Brasil sem Homofobia" que, a fim de combater a violência e a discriminação contra LGBTs e promover sua cidadania, contava com um grupo constituído especificamente para pensar em questões de saúde - o Comitê Técnico de Saúde LBGT (CTSLGBT), do Ministério da Saúde. Em 2006, como parte dos representantes da sociedade civil, o movimento LGBT foi incluído no Conselho Nacional de Saúde. Um resultado importante desses debates foi a inclusão da orientação sexual e identidade de gênero na análise de Determinantes Sociais de Saúde, aprovada em 2007 (Brasil, 2008). Com isso, a discriminação sexual era ratificada como fator que corrobora para o adoecimento e sofrimento das pessoas que a vivenciam.

Em 2011, foi instituído o Plano Nacional de Saúde Integral a LGBTs, visando garantir o atendimento universal, integral e equitativo à saúde LGBT.
Como estratégias, o plano vigora ações para buscar garantir o acesso, realizar a promoção e a vigilância em saúde, a educação permanente com foco nessa população e o monitoramento e avaliação das ações de saúde implementadas. O plano faz menção específica a necessidade especial de cuidados com a saúde mental dessas(es) usuárias(os), por serem alvos de uma variedade de discriminações sociais (Portaria n. 2.836, 2011).

Mesmo a partir de um conceito de saúde ampliado, que está presente na estratégia de saúde adotada pelo SUS, é perceptível o quanto as noções de saúde e adoecimento não consideram questões específicas presentes na vida de uma pessoa trans, mesmo em resoluções que eram voltadas para elas - tanto que muitos dessas normativas continuam sendo disputadas pelas/os usuárias/os. É o caso do processo transsexualizador, que passou a ser regulamentado por uma nova Portaria do Ministério da Saúde, a no 2.803, em 19 novembro de 2013 (Portaria n. 2.803, 2013). O novo texto ampliou os procedimentos contemplados para quem deseja realizar a cirurgia, estruturando um conjunto de cuidados que vão desde a atenção básica, compreendendo cuidados de saúde e atenção continuada, à especializada, com atendimento ambulatorial pré e pós-operatório, incluindo hormonioterapia e serviços hospitalares (Brasil, 2013).

Importante ressaltar a $15^{\text {a }}$ Conferência Nacional de Saúde como momento em que debates referentes à população LGBT foram pautados, principalmente associados à efetivação dos direitos conquistados no campo da saúde. Isso porque, muito frequentemente, as necessidades de saúde dessas pessoas ainda são vistas pelos agentes de saúde com estranhamento, desconhecimento e desrespeito - o que mantém esses usuários afastados do sistema. Um dos símbolos dessa diferença entre os direitos assegurados e o cotidiano nos serviços de saúde está no uso do nome social. Embora seja um direito garantido desde 2006, são comuns os relatos de não conformidade com a determinação - tanto que, a partir de 2012, se tornou possível que os Cartões do SUS fossem impressos apenas com o nome social da(o) usuária(o), como instrumento mais concreto para consolidar seu uso (Brasil, 2016).

As políticas públicas de saúde voltadas para a população trans são parte de uma luta para garantir condições de vida e de bem-estar biopsicossocial para uma população marcada pela violência, estigma e o 
preconceito. A constante disputa por ampliação dos serviços mostra a restrição do seu alcance frente às demandas das(os) usuárias(os) e, acima de tudo, a desigualdade no acesso a um Sistema de Saúde pautado na integralidade, universalidade e equidade.

\section{SUS enquanto ratificador de subjetividades normativas}

Grande parte da literatura acerca da garantia de acesso de pessoas trans ao SUS se restringe ao processo transexualizador, que engloba a cirurgia de redesignação sexual. Tal enfoque se traduz em um indicador das dificuldades de acesso e continuidade do cuidado de pessoas trans a outras demandas de saúde, assim como traz - e nos ajuda a colocar questões sobre o lugar do SUS enquanto ratificador de subjetividades normativas e/ou potencializador de singularizações.

O Ministério da Saúde determina que qualquer pessoa que procure o SUS apresentando queixa referente à "incompatibilidade entre o sexo anatômico e o sentimento de pertencimento ao sexo oposto ao do nascimento" tem direito a acompanhamento terapêutico com ênfase na reinserção social e atendimento humanizado. Por sua vez, para dar início aos procedimentos que fazem parte do processo transexualizador pelo SUS, é exigido que a pessoa se submeta à avaliação e acompanhamento de uma equipe multidisciplinar por um período determinado de no mínimo dois anos (Sampaio \& Coelho, 2012). É somente a partir de um laudo psiquiátrico que os procedimentos podem ser realizados, de modo que o psiquiatra ocupa uma posição classificatória de saber/poder; ele é o responsável por validar ou não vivências, decidir quais são aquelas(es) que receberão ou não "cuidado”. A lógica patologizante desconsidera a autonomia de pessoas trans a respeito de seu próprio corpo e sua própria vida e apresenta-se revestida como suposto cuidado, uma posição de tutela (Sousa \& Cavalcanti, 2016).

Sampaio e Coelho (2012) apontam que há um choque entre a construção da própria identidade por parte da experiência da pessoa trans e o poder concedido aos profissionais de saúde de definir o quão "real" ela é. Apesar de o Ministério da Saúde determinar que é resguardado à pessoa trans o direito às diferenças subjetivas e comportamentais, o protocolo estabelecido pelo SUS se baseia em normas biomédicas e binárias de sexo e gênero. Deste modo, trava-se uma espécie de jogo de convencimento, em que muitas vezes a pessoa que busca acesso ao processo transexualizador precisa se adequar a condutas pautadas na cisheteronorma e em lógicas universalizantes de masculinidade e feminilidade, mesmo que isso não corresponda a quem ela de fato é. Carregar o peso do estigma de um laudo psiquiátrico para ter acesso a uma cirurgia desejada, que se soma às opressões cotidianas vividas no contexto de uma sociedade LGBTfóbica, é mais um desrespeito à existência trans. Para Roconet al. (2016), a autoridade médica pautada na patologização deslegitima a autonomia de pessoas trans e as desloca do lugar de sujeitos de seus próprios processos, desautorizando-as de decidirem sobre as intervenções em seus próprios corpos, como fazem pessoas cis.

Compreender a transexualidade em sua multiplicidade de vivências singulares é um dos primeiros passos apontados por Áran, Murta e Lionço (2009) para combater sua psiquiatrização. Há, ainda, a importância de se problematizar a cirurgia de redesignação sexual como principal demanda de pessoas trans, levando em consideração realidades, necessidades e desejos distintos. Rocon et al. (2016) reiteram que a seletividade no processo transexualizador por meio do laudo psiquiátrico obstrui o acesso de pessoas trans ao SUS em diversos âmbitos, uma vez que traz o foco pra saúde pela negação da doença, o que não faz sentido no contexto da Constituição de 1988 que não condiciona o acesso ao SUS por meio da comprovação de uma patologia prévia.

A patologização dessas identidades gera estigmas e restrições sociais que têm efeitos concretos na condição de exclusão social, inclusive dentro do sistema de saúde. A garantia de acesso de pessoas trans ao SUS deve partir de um viés que as considere enquanto sujeitos de direitos e precisa ser mais ampla do que a realização do processo transexualizador (Áran et al., 2009). Dentre a população LGBT, as pessoas trans são as que apresentam as maiores dificuldades de acesso e permanência nos serviços ofertados pelo SUS - não somente em relação a procedimentos específicos como a cirurgia de redesignação sexual, mas também em ocasiões de demandas variadas. Isso se dá principalmente pela transfobia sofrida nos serviços de saúde, atrelada a outras opressões referentes à cor, raça e classe, por exemplo. $\mathrm{O}$ desrespeito ao nome social é apontado como um dos fatores chave não só na dificuldade de acesso, mas também no que diz respeito ao abandono ao longo 
do tratamento. Há relatos de recusa por parte do estabelecimento de saúde em atender a(o) paciente trans, de desrespeito à identidade de gênero em casos de internação hospitalar e de resistência de pessoas trans em buscarem serviços de saúde provocada pela discriminação (Roconet al., 2016).

Ao tomar a precariedade no acolhimento como fator determinante para a exclusão do sistema, Áran et al. (2009), propõem o combate a discriminação como estratégia de promoção de saúde, com o objetivo de deslocar a saúde de pessoas trans exclusivamente do eixo médico-cirúrgico e contemplar os sujeitos em sua integralidade, por meio do respeito às diferentes formas de vida.

\section{Produzindo vivências vitais}

"Questões feitas de vida". Definição mais precisa - já que, paradoxalmente, não pretende uma definição objetificada - acerca do que faz a Psicologia e de com o que ela trabalha; a despeito de abordagem teórica, a vida, enquanto um direito a ser exercido de forma singular - mas promovido coletivamente - deve ser o fio condutor de qualquer metodologia de intervenção psicológica (Resolução n. 10, 2005).

Desse modo, falar em vida transforma-se em um grande guarda-chuva, abarcando diversos fenômenos que passam a ser vistos de forma ampla e conectadaentre eles a saúde e o direito a ela. Contudo, é preciso partir do reconhecimento da inexistência de uma(um) sujeita(o) universal, a quem seriam direcionados os esforços dos profissionais nos serviços de saúde, convocando-nos a lidar com singularidades múltiplas, marcadas por vetores complexos e que exigem nossa atenção, assim como necessidades de saúde diversas (Peduzzi, Norman, Germani, Silva, \& Souza, 2013). Em se tratando do atendimento às pessoas trans no contexto do Sistema Único de Saúde, tal observação não é diferente: cada sujeita(o) apresenta necessidades de saúde distintas, principalmente na medida em que se integram à produção de vida e à criação de condições para vivê-la.

Contudo, sob efeitos da cisgeneridade enquanto dispositivo de regulação potente dos corpos e modos de existência (Sousa \& Cavalcanti, 2016), as políticas públicas de saúde parecem preconizar as intervenções cirúrgicas de redesignação sexual enquanto únicas - ou principais - demandas dessa população, atualizando a lógica binária de gênero e seus mecanismos normativos. Nesse aspecto, Rocon, Sodré, Zamboni,
Rodrigues e Roseiro (2018) contribuem, em resultados de estudos com pessoas trans na Grande Vitória/ES, com os apontamentos de que, entre as participantes mulheres transexuais e travestis, "o implante de prótese mamária, a hormonioterapia e os cuidados integrais e multiprofissionais [grifo nosso] parecem destacar-se em relação às cirurgias de redesignação sexual" (p. 51).Como já apontado, no que diz respeito às dificuldades enfrentadas por essa população no acesso aos serviços de saúde, o desrespeito ao nome social, a discriminação e o diagnóstico no processo transexualizador apresentam-se enquanto as principais limitações (Roconet al., 2016). A problemática do diagnóstico não é nova para os saberes Psi, principalmente em sua relação com a patologização das vivências trans* e com um aparato médico-jurídico produtor de verdades e discursos e, consequentemente, de subjetividades (Foucault, 2001; Cavalcanti et al., 2018); no, pelo e para o diagnóstico, racionalidades conflitantes disputam, em várias esferas, sendo considerado essencial na prevenção de arrependimentos posteriores aos procedimentos cirúrgicos por alguns - considerados especialistas - ou estratégia única na garantia dos serviços de saúde à população trans por outros (Bento \& Pelúcio, 2012).

No contexto da Atenção Primária em Saúde, a Psicologia tem um histórico marcado pela busca por um lugar social, isto é, pelo reconhecimento enquanto categoria profissional tão necessário após os primeiros indícios da insuficiência do modelo clínico individualizante, característico do período pré-redemocratização do país (Gil, 1985). Desde então, psicólogas e psicólogos passaram a trabalhar em diversos níveis, tendo sua atuação prescrita em forma de lei sempre de modo a colocá-las nesta posição de especialistas, responsáveis pela expertise em saúde mental.

Aqui, cabe retomarmos o princípio da integralidade, norteador do Sistema Único de Saúde, na medida em que "busca garantir ao indivíduo uma assistência à saúde que transcenda a prática curativa, contemplando o indivíduo em todos os níveis de atenção e considerando o sujeito inserido em um contexto social, familiar e cultural" (Souza et al., 2012). Nesse sentido, é urgente insistir na denúncia de que o diagnóstico contribui para ocultar a responsabilidade da cisgeneridade e do binarismo de gênero pela marginalização social das pessoas trans, ao mesmo tempo em que transfere o poder de legitimação de suas vivências para profissionais 
de saúde que mais tutelam que cuidam. Dignas de nota são as orientações de Nota Técnica do Conselho Federal de Psicologia acerca do processo transexualizador e demais formas de assistência às pessoas trans (set/2013) de que o processo psicoterapêutico, requerido pela Portaria no 1.707/2008 do Ministério da Saúde, não se restringe à tomada de decisão sobre cirurgias de redesignação sexual e demais maneiras de modificação corporal, mas antes tem por objetivo a promoção da autonomia da pessoa e de atenção às suas necessidades singulares.

Percebe-se que, mesmo com a consideração de uma prática que não seja exclusivamente curativa, ou seja, que também se atenha à prevenção dos diversos processos de adoecimento, a integralidade em saúde muitas vezes não encontra na visão integral de saúde um sinônimo, já que foi - e ainda é, em grande medida - marcada pela visão de soma das partes proveniente do modelo biomédico. Nesse sentido, os efeitos da luta antimanicomial e os encaminhamentos da Lei ${ }^{\circ}$ 10.216/2001 demonstram-nos contribuições da Psicologia caras à saúde - e, eis aqui o ponto do argumento: não somente à saúde mental, mas a uma concepção integral de saúde, principalmente no que diz respeito à articulação na rede. ${ }^{1}$

É nesse aspecto que a atuação da Psicologia na Atenção Primária pode ser muito útil, na medida em que tal articulação seja encarada enquanto uma tecnologia de intervenção capaz de materializar a tão almejada saúde integral, entendida "como um processo singular e subjetivo de negociação permanente de sentidos em um campo social, processo de construção e de desconstrução de normas para o enfrentamento da realidade e da (re)qualificação da vida" (Dimenstein \& Macedo, 2012, p. 234).

Tecnologia, no contexto da saúde, entendida enquanto conjunto de instrumentos materiais e não materiais na produção dos serviços; assim,

As práticas do trabalho na atenção básica devem incluir diversas tecnologias de maneira adequada, conforme as necessidades de saúde, que são as ações e os serviços de saúde dos quais os sujeitos precisam para ter melhores condições de vida, sem prejuízo do atendimento (Coelho \& Jorge, 2009, p. 1524).
Em referência à Merhy, as autoras apontam que as tecnologias podem ser classificadas como leve, leve-dura e dura, relacionadas principalmente às relações, aos saberes estruturados e aos recursos materiais, respectivamente (Coelho \& Jorge, 2009). Pensando articulação na rede, podemos concebê-la enquanto tecnologia leve, na medida em que é atravessada pelos processos de acolhimento, vínculo e atenção integral como gerenciadores das ações de saúde, quais sejam sua promoção, a prevenção das doenças, a recuperação da saúde e a humanização do atendimento.

É evidente que a articulação na rede não deve ser tarefa exclusiva da Psicologia, já que a própria diretriz de hierarquização do SUS reconhece níveis articulados de atenção, assim como os outros profissionais que nele estão inseridos. Contudo, não é mera coincidência que psicólogas estejam presentes em diversos desses níveis de atenção em saúde e outras políticas públicas, seja no Núcleo de Apoio à Saúde da Família (NASF), nos ambulatórios, na Rede de Atenção Psicossocial (RAPS), no Centro de Referência em Assistência Social (CRAS) e em outros espaços. É justamente por defender uma visão integral de saúde - que inclui outros direitos básicos - e reconhecer a(o) usuária(o) enquanto sujeita(o) ativa(o) (mas não exclusivamente responsável pelo seu processo de reabilitação) que o trabalho das psicólogas na Atenção Primária pode ser mais eficaz, desde que seja capaz de conectá-las(os) a essa rede de garantia de direitos, fornecendo ferramentas para sua autonomia.

Em um contexto em que as políticas de saúde para a população trans seguem ainda entendidas como elementos da alta complexidade, uma vez que todos os cuidados são capturados por uma suposta necessidade de cirurgia como demanda suprema de todo o segmento, apostar na atenção primária como espaço de acolhimento e cuidado produz potências múltiplas na garantia de acessos e de direitos. Por um lado, o caráter territorializado de um acompanhamento integral e preventivo, quando atento para as linhas de exclusão que atravessam as pessoas trans mesmo em seus territórios, pode ser importante estratégia de vinculação e produção de redes de proteção muito próximas. O caráter preventivo dos acompanhamentos também, por sua vez, supre uma série de pequenas necessidades, desafogando as imensas filas

\footnotetext{
${ }^{1}$ No âmbito da Atenção Primária, ações preventivas em Saúde Mental passaram a ser incentivadas e pautadas em documentos oficiais, mesmo que a presença de profissionais teoricamente responsáveis por essa expertise nas Unidades Básicas de Saúde somente aconteça pela via do Núcleo de Apoio à Saúde da Família (NASF), ou seja, em caráter de apoio.
} 
de espera para os poucos serviços especializados no país e sanando os grandes índices de automedicação - realidade da absoluta maioria das pessoas trans (Roger, Tesser, Moretti-Pires, Kovaleski, 2016).

Um efeito secundário de fomentar o atendimento às pessoas trans na atenção básica é a necessária rearticulação de toda uma rede de poder que se organiza ao redor e a partir dos grandes centros da alta complexidade. Tal composição decorre do que podemos, junto a Foucault (2001), entender como um modo muito específico de enunciação e nomear como discursos de especialistas. Historicamente, cabia ao psiquiatra agenciar todo o caminho percorrido pelas pessoas trans no campo do acesso à saúde, posto que, uma vez que a experiência não cisgênera era entendida como uma comorbidade psicopatológica, tornou-se senso comum a percepção de que este seria o principal "especialista" a recorrer. Tais centralizações são completamente deslocadas com a modificação anunciada pela OMS ao afirmar que as vivências trans não dizem respeito ao campo das patologias mentais. Com este enunciado, para de ser justificável que seja justamente o psiquiatra o profissional a organizar os serviços para a população trans, o que desloca esta especialidade como apenas mais uma ofertada pelo rol de procedimentos em saúde, mas em nada mais necessária para uma transição de gênero do que um dermatologista, ou um otorrino ou qualquer outra especialidade médica disponibilizada para especificidades singulares, não compulsoriamente para todo o segmento de pessoas trans. A atenção básica, aqui novamente ressaltamos, dada a sua proposta de cuidado integral, localizado e multiprofissional, pode ser, por si, campo desarticulador do poder médico centrado na norma cisgênera.

\section{Considerações finais}

Ao regulamentar o reconhecimento da autodeterminação de identidade de gênero no exercício profissional, a Resolução $n^{\circ} 1$ do Conselho Federal de Psicologia (Resolução $n .1,2018$ ) ganha destaque na medida em que se apresenta como força discursiva da profissão em uma matriz que não lhe é objeto exclusivo quando, em seu artigo terceiro, postula: "As psicólogas e os psicólogos, no exercício profissional, não serão coniventes e nem se omitirão perante a discriminação de pessoas transexuais e travestis" (Resolução n. 1, 2018). Dizer que as necessidades de saúde das pessoas trans não são objeto exclusivo da Psicologia significa ratificar a necessidade de pensar a participação desta junto aos demais profissionais do SUS, articulando-se micro e macropoliticamente em prol da preservação dos direitos humanos; em outras palavras, "é preciso reconhecer a Psicologia como um campo de saber capaz de promover tensões no discurso biomédico patologizante e construir outras bases para o diálogo entre as categorias profissionais, para além daquelas que catalogam e esquadrinham vivências em patologias" (Sousa \& Cavalcanti, 2016, p. 137).

Tal diálogo consiste em grande potência de invenção e não tem por objetivo um consenso, mas tomar como ponto de partida um comum: a produção de cuidado efetivo. Para tanto, nas palavras de Dimenstein e Macedo (2012), precisamos "dispor-nos à experimentação, ativar a ousadia de diferir, [...] afastando-nos da inclinação ao congelamento, desinvestindo práticas idealizadas e o engessamento por referenciais transcendentes e universalizantes" (p. 238). Ativar a ousadia de diferir, nesse sentido, pode significar envolver-se, no âmbito da Atenção Primária, na busca ativa das(os) usuárias(os) trans, criando metodologias que permitam a vinculação e a apropriação dos serviços por parte dessa população. Roconet al. (2018), apontam, por exemplo, as dificuldades que podem existir na relação entre estas usuárias e os Agentes Comunitários de Saúde, percebidos por estas como "despreparados", "sem propriedade" e "com vergonha de se aproximar".

Além dos dispositivos já contidos em documentos e cartilhas do Ministério da Saúde (Brasil, 2013) - como os grupos terapêuticos, o matriciamento e outros - uma ação que merece a atenção da Psicologia no âmbito da Atenção Primária é a educação popular em saúde, a partir do momento em que esta se propõe a fomentar a autonomia dos usuários e articulá-los entre si. Sendo assim, quando falamos em articulação de rede como uma tecnologia de intervenção da Psicologia, referimo-nos à articulação mútua entre usuários, profissionais de saúde - entre eles as próprias psicólogas - e políticas públicas, tendo como fio condutor a integralidade em saúde e a atuação interdisciplinar.

Desse modo, antes de localizarmos a responsabilidade de uma estrutura transfóbica e cisnormativa em uma ou outra categoria profissional, é nosso dever analisarmos, antes de tudo, que práticas temos produzido, quais os seus objetivos e efeitos produzidos na direção de "eliminação de quaisquer formas de negligência, discriminação, exploração, violência, crueldade e opressão" (Resolução n. 10, 2005). Pos- 
teriormente, construir relações com e fornecer subsídios para as demais categorias profissionais envolvidas nos serviços de saúde, conectando-se em vistas do estabelecimento de um campo de produção de cuidado colaborativo e, consequentemente, efetivo. É sempre redundante dizer que essa tarefa não é fácil.
A realidade dos fatos nunca foi e, dado o aumento de propostas de sucateamento e desmonte de sistema que luta continuamente para se manter de pé, não o será tão cedo. Cabe a nós articularmos forças em vistas de garantir o direito à saúde e, mais que tudo, direito à existência de todas e todos.

\section{Referências}

Áran, M., Murta, D., \& Lionço, T. (2009). Transexualidade e saúde pública no Brasil. Ciência e Saúde Coletiva, 4(14), 1141-1149. https://doi.org/10.1590/S1413-81232009000400020

Bento, B., \& Pelúcio, L. (2012). Despatologização do gênero: A politização das identidades abjetas. Estudos Feministas, 20(2), 559-68. https://doi.org/10.1590/S0104-026X2012000200017

Brasil. Ministério da Saúde. (2005). Transexualidade e travestilidade na saúde. Brasília, DF: o autor.

Brasil. Ministério da Saúde. (2008). Relatório final: 13ª Conferência Nacional de Saúde. Brasília, DF: o autor.

Brasil. Ministério da Saúde. (2013). Cadernos de atenção básica: saúde mental. Brasília, DF: o autor.

Brasil. Ministério da Saúde. (2016). Atenção integral à saúde da população trans. Brasília, DF: o autor.

Cavalcanti, C., Carvalho, M. W. V., \& Bicalho, P. P. G. (2018). A estranha liberdade de odiar: Uma análise do processo de Ação Civil Pública contra a resolução 01/2018 do Conselho Federal de Psicologia. Periódicus, 10(1), 231-249. https:// doi.org/10.9771/peri.vli10.27943

Coelho, M. O., \& Jorge, M. S. B. (2009). Tecnologia das relações como dispositivo do atendimento humanizado na atenção básica à saúde na perspectiva do acesso, do acolhimento e do vínculo. Ciência \& Saúde Coletiva, 14(1), 1523-1531. https://doi.org/10.1590/S1413-81232009000800026

Dimenstein, M., \& Macedo, J. P. (2012). Formação em Psicologia: Requisitos para atuação na atenção primária e psicossocial. Psicologia: Ciência e Profissão, 32 (num. esp.), 232-245. https://doi.org/10.1590/S141498932012000500017

Foucault, M. (2001). Os anormais. São Paulo, SP: Martins Fontes.

Gil, A. C. (1985). O psicólogo e sua ideologia. Psicologia: Ciência e Profissão, 5(1), 13-17. https://doi.org/10.1590/ S1414-98931985000100005

Jones, Z. (2019, abril 7). "Disforia de gênero de início rápido" (DGIR): uma fraude pseudocientífica que mira os jovens transgêneros e suas famílias [Blog]. Recuperado de: https://medium.com/@biapagliarinibagagli/disforia-de-g\%C3\%AAnero-de-in\%C3\%ADcio-r\%C3\%Alpido-dgir-uma-fraude-pseudocient\%C3\%ADfica-que-mira-os-jovens-743e4df65641

Missé, M. (2010). El género desordenado: Críticas en torno a la patologización de la transexualidad. Barcelona: Egales.

Peduzzi, M., Norman I. J., Germani, A. C. C. G., Silva, J. A. M., \& Souza, G. C. (2013). Educação interprofissional: Formação de profissionais de saúde para o trabalho em equipe com foco nos usuários. Revista da Escola de Enfermagem da USP, 47(4), 977-983. https://doi.org/10.1590/S0080-623420130000400029

Popadiuk, G. S., Oliveira, D. C., \& Signorelli, M. C. (2017). A política nacional de saúde integral de lésbicas, gays, bissexuais e transgêneros (LGBT) e o acesso ao processo transexualizador no Sistema Único de Saúde (SUS): Avanços e desafios. Ciência \& Saúde Coletiva, 22(5), 1509-1520. https:// doi.org/10.1590/1413-81232017225.32782016

Portaria No 2.836, de $1^{\circ}$ de dezembro de 2011. Institui, no âmbito do Sistema Único de Saúde (SUS), a Política Nacional de Saúde Integral de Lésbicas, Gays, Bissexuais, Travestis e Transexuais. Diário Oficial da União, 5 dez. 2011.

Portaria No 2.803, de 19 de novembro de 2013. Redefine e amplia o Processo Transexualizador no Sistema Único de Saúde (SUS). Diário Oficial da União, 20 dez. 2013.

Preciado, P. B. (2014). Manifesto contrassexual. São Paulo, SP: N-1.

Resolução № 10, de 27 de agosto de 2005. Aprova o código de ética profissional do psicólogo. Brasília, DF: Conselho Federal de Psicologia. 
Resolução № 1, de 29 de janeiro de 2018. Estabelece normas de atuação para as psicólogas e os psicólogos em relação às pessoas transexuais e travestis. Brasília, DF: Conselho Federal de Psicologia.

Rocon, P. C., Rodrigues, A., Zamboni, J., \& Pedrini, M. D. (2016). Dificuldades vividas por pessoas trans no acesso ao Sistema Único de Saúde. Ciência \& Saúde Coletiva, 21(8), 2517-2525. https://doi.org/10.1590/141381232015218.14362015

Rocon, P. C., Sodré, F., Zamboni, J., Rodrigues, A., \& Roseiro, M. C. F. B. (2018). O que esperam pessoas trans do Sistema Único de Saúde? Interface (Botucatu), 22(64), 43-53. https:// doi.org/10.1590/1807-57622016.0712

Roger, J., Tesser, Z. C., Jr., Moretti-Pires, R. O., \& Kovaleski, D. F. (2016). Pessoas trans na atenção primária: Análise preliminar da implantação no município de Florianópolis, 2015. Saúde \& Transformação Social, 7 (3), 49-58.

Sampaio, L. L. P., \& Coelho, M. T. Á. D. (2012). Transexualidade: Aspectos psicológicos e novas demandas ao setor saúde. Interface (Botucatu), 16(42), 637-649. https://doi.org/10.1590/S1414-32832012000300005

Sousa, D., \& Cavalcanti, C. (2016). Entre normas e tutelas: pensando (im)possibilidades da Psicologia em interface com transgeneridades. In A. Denega, D. S. V. Andrade, \& H. M. Santos (Orgs.), Gênero na psicologia: Saberes e práticas (pp. 126-139). Salvador, BA: CRP-03.

Souza, M. C., Araújo, T. M., Reis, W. M., Jr., Souza, J. N., Vilela, A. B. A., \& Franco, T. B. (2012). Integralidade na atenção à saúde: um olhar da Equipe de Saúde da Família sobre a fisioterapia. O Mundo da Saúde, 36(3), 452-460.

Vergueiro, V. (2016). Por inflexões decoloniais de corpos e identidades de gênero inconformes: uma análise autoetnográfica da cisgeneridade como normatividade (dissertação). Instituto de Humanidades, Artes e Ciências Professor Miltons Santos, Universidade Federal da Bahia, Salvador, BA, Brasil.

\section{Erick da Silva Vieira}

Discente do curso de graduação em Psicologia da Universidade Federal do Rio de Janeiro (UFRJ), Rio de

Janeiro - RJ. Brasil.

Email: ericksilvieira@gmail.com

(iD https://orcid.org/0000-0003-0317-4762

\section{Clarissa Viola Dutra}

Discente do curso de graduação em Psicologia da Universidade Federal do Rio de Janeiro (UFRJ), Rio de Janeiro - RJ. Brasil.

E-mail: clarissavdutra@gmail.com

(iD https://orcid.org/0000-0003-4268-7261

\section{Carlos Allencar Servulo Rezende Pereira}

Discente do curso de graduação em Psicologia da Universidade Federal do Rio de Janeiro (UFRJ), Rio de Janeiro - RJ. Brasil.

E-mail: rezende.alencar@gmail.com

(iD) https://orcid.org/0000-0002-6930-3312

\section{Céu Silva Cavalcanti}

Psicóloga. Mestre em Psicologia. Discente do curso de Doutorado em Psicologia da Universidade Federal do Rio de Janeiro (UFRJ), Rio de Janeiro - RJ. Brasil. Bolsista CNPq.

E-mail: ceucavalcanti@gmail.com

(iD) https://orcid.org/0000-0001-9007-1600

Endereço para envio de correspondência:

Av. Pasteur, 250 - Pavilhão Nilton Campos, Campus Praia Vermelha, Urca - Rio de Janeiro - RJ. Brasil.

CEP: 22290-902 
Recebido 10/09/2019

Aceito 04/10/2019

Received 09/10/2019

Approved 10/04/2019

Recibido 10/09/2019

Aceptado 04/10/2019

Como citar:Vieira, E. S., Dutra, C. V., Rezende-Pereira, C. A. S., Cavalcanti, C. S. (2019). Psicologia e Políticas de Saúde da PopulaçãoTrans: encruzilhadas, disputas e porosidades. Psicologia:Ciênciae Profissão,39(n.spe3), 161-173. https://doi.org/10.1590/1982-3703003228504

How to cite:Vieira, E. S., Dutra, C. V., Rezende-Pereira, C. A. S., Cavalcanti, C. S. (2019). Psychology and Trans Population Health Policies: crossroads, disputes and porosities. Psicologia: Ciência e Profissão, 39(n.spe 3), 161-173. https://doi.org/10.1590/1982-3703003228504

Cómo citar:Vieira, E. S., Dutra, C. V., Rezende-Pereira, C. A. S., Cavalcanti, C. S. (2019). Psicología y Políticas de Salud da Población Trans: encrucijadas, disputas y porosidades. Psicologia: Ciência e Profissão, 39(n.spe 3), 161-173. https://doi.org/10.1590/1982-3703003228504 